
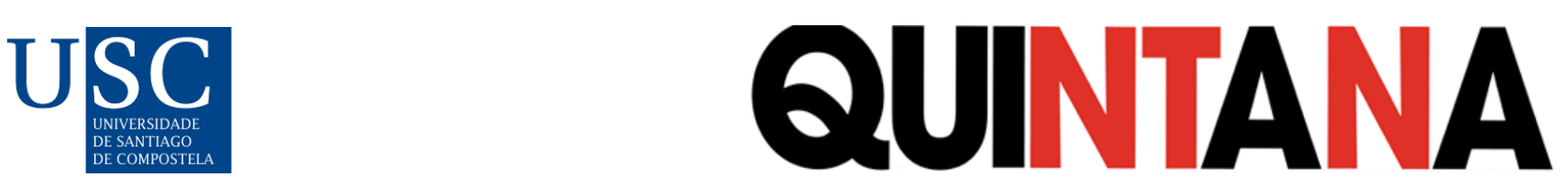

Quintana: revista do Departamento de Historia da Arte, (20), 2021. ISSN-e: 2340-0005

https://doi.org/10.15304/quintana.20.7471

Colaboracións

\title{
REN HANG'S PHOTOGRAPHIC WONDERLAND: AN ANALYSIS OF HIS GENDERLESS VISUAL LANGUAGE
}

\author{
Maite Luengo Aguirre \\ Universidad del País Vasco UPV/EHU and Université Bordeaux Montaigne, España \\ maite.luengo@ehu.eus
}

Recibido: 04/02/2021; Aceptado: 28/05/2021

\begin{abstract}
The work of the Chinese photographer and poet Ren Hang (1987-2017) was received internationally by emphasising the sexual content and revolutionary character of the use of naked bodies. Nonetheless, the recent years after his death have led to a diversification of investigations in reference to his polysemic photography. This article aims to contribute to the pluralization of the readings around his work, having developed an investigation on the visual genderless treatment of the people posing for him. For this purpose, firstly, the article departs from the revision of the European reception of his work, followed by the study of the significance of nakedness and gender. Then, the identification and investigation of the specific elements within the work of the artist that contribute to a possible genderless reading is undertaken.
\end{abstract}

Keywords: Ren Hang; photography; body; nude; gender.

\section{Resumen}

La obra del fotógrafo y poeta chino Ren Hang (1987-2017) fue recibida en el contexto internacional destacando su contenido sexual y el carácter revolucionario del uso de cuerpos desnudos. Sin embargo, los recientes años póstumos han dado paso a la diversificación de investigaciones referentes a su polisémica fotografía. Este artículo propone una contribución al actual proceso de pluralización de aproximaciones, habiendo desarrollado una investigación en torno al tratamiento visual sin género de las personas que posaban para él. Para ello, primeramente, se parte de la revisión de la recepción europea de su obra, acompañada del estudio del significado de la desnudez y del género. A continuación, se realiza la identificación e investigación de los elementos concretos hallados dentro de su obra que contribuyen a una posible lectura sin género.

Palabras clave: Ren Hang; fotografía; cuerpo; desnudo; género. 


\section{INTRODUCTION}

The photographer and poet Ren Hang (Changchun, 1987 - Beijing, 2017) left a vast legacy of more than a thousand images showing naked models in a variety of postures. His work has continued to be exhibited in Europe after his decease, as his popularity continued to increase. Unfortunately, within this context, his complex images have been frequently reduced to a reading based on their potential sexual content. Because of his short as well as intense career, there have not been yet much research regarding his art. Nevertheless, in the recent years researchers are showing an increasing interest towards his work, creating new readings emerging from a variety of disciplines.

A sign of this new turn was the final project by an Erasmus Mundus Master's Degree in Women's and Gender Studies student. Indeed, Xu Jiachen analysed the relation between queer bodies and the non-humans in Ren Hang's photography. She departed from a sociological approach emphasising the links between the queer of colour and the non-human element (2018). More recently, Nicholas Gamso wrote a publication for the journal of the Asia Art Archive, where he discussed the relationship of the photographer's work with the city, focusing on queer body politics (2019). Likewise, young researcher Ada Quondamatteo from the University of Bologna wrote about the psychological aspects of the poetry by Ren such as depression, the experience of loneliness and self-perception (2020).

Indeed, if anything, Ren's work can have many different readings, as people that worked with him and his photographs acknowledge. In an interview, even the model Ke Xin, who posed for Ren Hang, talked about the mix of dirtiness and purity that the images had to her (VICE Japan 2013) ${ }^{1}$. This variety of depictions offers the chance to make different readings that may even one contradict the other. But it is there where the richness of his work lies, endless readings arising from it, as curator Thomas Dukes has indicated ${ }^{2}$.

In this article, I intend to contribute to this diversification tendencies, as they seem to be the best tool to understanding the polysemic work of the photographer. Thus, I propose redirecting the discussion towards the genderless aspect of his work, since his photographs can be valuable contributions to the development of queer aesthetics.

This practice of challenging and reflecting on gender norms through renewed aesthetics, as well as experimenting with the flesh, has some precedents within contemporary photography. Concerning the Western artistic creations, I would like to mention two artistic couples and romantic partners, which were influenced by surrealism. In the 1920s and 1930s, Claude Cahun and Suzanne Malherbe (better known as Marcel Moore), created works mainly consisting of portraits and selfportraits playfully combining female and male elements, thus, exploring gender fluidity. Then, Hans Bellmer and Unica Zürn are to be named. In a series of images known as Untitled (Unica Bound) (1958), Zürn was photographed by her husband, while she was tied with a cord that deformed her female body in a disturbing manner.

Furthermore, there has also been relevant photographic work developed in the Chinese context reflecting on gender and bodies, especially in the 90s. During this period of time, Xing Danwen created I am a woman (1994-1996), a series of photographs she took of other women without clothes, in representation of her inner questions. Similarly, related with femininity but erasing borders with masculinity, performance artist Ma Liuming created an alter ego named Fen Ma 
Liuming. In the image Fen Ma Liuming's Lunch (1994), we can identify the ambiguous identity he created by utilising his feminine facial traits in combination with his nude cisgender male body.

This lack of clarity in gender classification is also present in the work by two artists who approached bodies associated with nature in a non-binary way. Firstly, Cang Xin in collaboration with Zhang Huan created the work To Add One Metre to an Anonymous Mountain (1995) in which naked bodies appeared piled on top of a mountain, adding an additional metre heigh with their flesh, with no gender distinction. Secondly, in the early $21^{\text {st }}$ century, Liu Wei captured nether parts of bent bodies It looks like a landscape (2004) creating a renewed landscape simulating traditional Chinese ink drawing.

Once previous cases have been presented, I will proceed to the analysis of the work by Ren Hang. In order to study the genderless aesthetic contribution that Ren made to contemporary art, I begin by examining the European reception, focusing on the curatorial selections regarding both photobooks and exhibitions. Then, I present the approach that the artist had towards nudity and gender. Finally, I identify and study the visual elements of his photographic corpus, in order to develop a new reading of his work.

\section{THE EUROPEAN RECEPTION AND BEYOND}

In order to understand the general vision of the artist's work developing in Europe, I will present some of the milestones from the beginning. There are two important figures at the start of his international career: Ai Weiwei and Pierre Bessard. First contacts with the Old Continent came thanks to Ai Weiwei, who invited Ren Hang to participate in the exhibition FUCK OFF 2 in 2013 at the Museum of Groningen ${ }^{3}$. A year later, the French publishing house specialised on photography Éditions Bessard, printed a limited edition of 500 photobook of the artist titled: The Brightest Light Runs Too Fast. The artist used to work with fanzines back in China, which were of humbler dissemination by nature. So, this publication in collaboration with the French editor was an essential impulse in his career because it succeeded in reaching a broader public.

Another important milestone is the extensive photobook edited by the well-known publishing house Taschen in 2016. Up until now, this is the biggest photobook publication of his work available to the public. Now his website has disappeared; this book is an important tool to understand the narrative provided in this broad edition available to readers. The selection of the images was mostly composed of those showing the genitalia and sexuality in a quite straightforward manner (Ren and Hanson 2016). This accounts for one part of Ren's work, which underlines the hypersexual. However, it may create difficulties for the audience in having a complete comprehension of Ren's body of work. 
Fig. 1. Ren Hang, 2012. Image courtesy of Ren Hang/ Galerie Paris-Beijing.

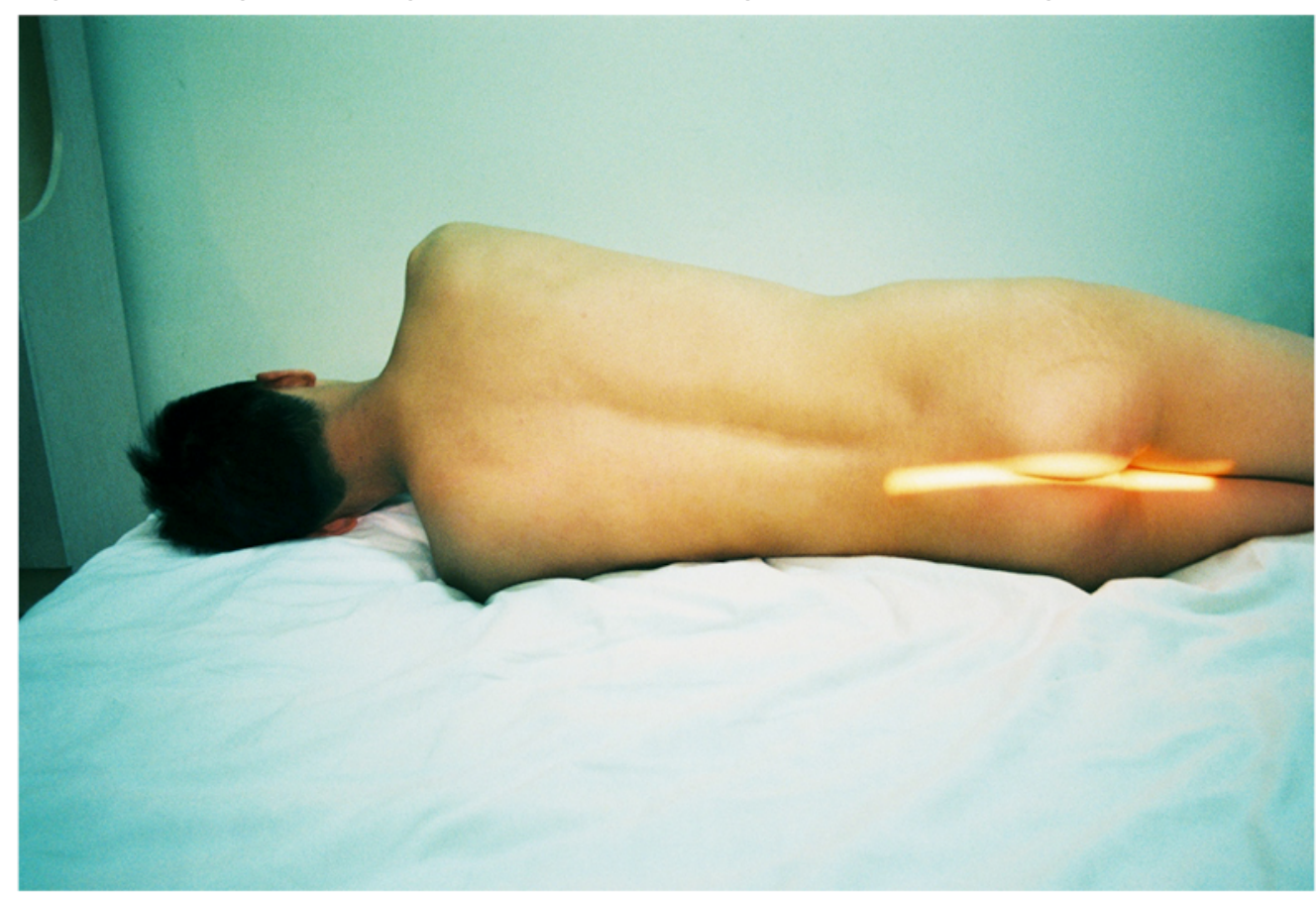

Another point to be considered, is that the images showing naked bodies are not pornographic by themselves, but they become so in the viewer's mind. Thus, seeing pornographically could be defined as staring at something for sexual excitement. Indeed, Stephen Mumford argues that the pornographic element comes in the gaze of the observer and that two different people can see the same thing in two very different ways. He even suggested that people may see things differently, depending on their gender (2013). In relation to the gaze and pleasure, researcher Chen Shuxia has maintained that in Ren's photographs, there is a voyeuristic relationship between the viewer and the bodies due to nakedness, youth and the fantastical compositions (2018). Moreover, Brad Feuerhelm even argued that "there is almost a voyeuristic tourism involved by the Western eye bound to the boom of his career" (2015). Consequently, not only does gender affect the viewing experience, but also the socio-cultural background; probably, the reception in Europe has been largely affected by this way of seeing as well. Also, the fact that the models were asked to pose hiding their face, may have facilitated this voyeuristic practice, as it can be seen in the image below (fig. 1). ${ }^{4}$

There are yet other assumptions that have been made when describing the work by Ren Hang, which has to do with superficiality, together with ideas related to the revolutionary. An example of the combination of these elements, is the solo exhibition Love, Ren Hang. This major display of 150 images at the European House of Photography in Paris was held from March 2019 to May 2019, in which the "naked revolutionary" idea was underlined. The curatorial approach was mostly organized in a chromatic and stylistic way, gathering images that were aesthetically matching, which could have been completed with some insight into the different narratives. This exhibition was later displayed at C/O Berlin Foundation with the same title, from December 2019 to February 2020. Due to the large number of artworks shown in these exhibitions, I consider them together with Taschen publication as the most influential towards the public, consequently creating a superficial narrative around his work. 
Fortunately, there are other alternative readings that have been done, such as the exhibition at the Open Eye Gallery in Liverpool. The display invited the audience to reflect on Ren Hang's photography from another perspective: thinking about the affectivity, as it was part of the collective exhibition Wake Up Together displayed along with Robin Hammond and held between 2018 and 2019. It was organized in the context of Homotopia Festival 2018, an art and heritage festival dedicated to the LGBT+ community. In this direction, we find the exhibition held in Italy at the Centro per l'arte contemporanea Luigi Pecci from June to August 2020. An exhibition that in the website introduction already underlined the variety of perspectives approaching Ren's work, by even mentioning the lack of importance of gender that I argue in this article.

Nevertheless, one may argue that the superficiality of the curating style in some of the exhibitions, may correspond to the supposed frivolity of Ren Hang's work. It is certainly a reading that may arise. This superficiality was signaled by Ai Weiwei, while defending the existence of deep meanings in Ren's work. Indeed, Ai referred to the late images by Ren Hang as "poetic and full of sadness" (Genova 2017). A contradictory interpretation that can be understood regarding the complexity of his work. Curator Zhang Yuli, who co-curated the exhibition at Shanghai's Modern Art Base between July and August 2017, argued that there was an unavoidable contrast in the work of Ren: while the images may result as visually bright, they have a dark side (Liang 2017).

The artists himself stated that there was no symbolism behind the work, that it was just for fun. But photography is not objective, as it is a way of seeing the reality that has been captured. So consciously or unconsciously, conventions, desires and beliefs are projected into the artwork (Elkins 2007). In the interview with Ren's French editor, Pierre Bessard, he told me that even if he did not consider there to be a hidden meaning in the elements, he acknowledged the artist had a very developed poetic language, in which clear influences from Lin Zhipeng could be appreciated ${ }^{5}$. These could range from the use of the naked body, to including flowers and animals, and even similar backgrounds. Then, as Ren's work developed, it differed more from the artist that pioneered the concept of private photography in China. It seems that discrepancy around Ren's work is to be understood as a constituting part of itself.

\section{ON THE LIMITS OF NUDITY}

In Europe, we are used to consider nakedness being part of our artistic heritage. Since Ancient Greece, nudes in the artistic practices have been common in order to explore the concept of beauty. However, this has not been a genre in traditional or early contemporary Chinese art. Nakedness in China has traditionally been linked with a lack of morality in terms of exhibiting what should be part of privacy and, hence, was not particularly popular within the artistic practice back in the 80s (Kristof 1989). In relation to contemporary Chinese history, nudity was officially banned since the creation of the People's Republic of China in 1949.

Nevertheless, in the 80s, there was a slight change of attitude towards the nude. In 1984, nude models were officially admitted again into the art schools, in order to explore the beauty of the body (The Economist 1989). In 1989 the first exhibition of nudes opened at the Beijing Art Gallery. The 1990s were a time when extreme performances happened and the bodies were more closely related to suffering and violence, rather than they were to beauty. Consequently, later in 2001, the government responded to this kind of practice with a decision dictated by the Ministry of Culture of China, announcing the "Resolution to Cease All Performances and Bloody, Brutal Displays of 
Obscenity in the Name of Art", making some forms of nudity undesirable, and showing that it was still quite a taboo in Chinese society (Wu and Wang 2010, 277).

This event confirmed that the display of nudity remains a subject of discussion. Nonetheless, artists using naked bodies do not necessarily do it in a dissident way towards the government, but rather as a way of mere exploration of nakedness. Outside of China, artists that are being censored seem to have a certain aura that emphasizes the effect of their work, which sometimes overshadows one's understanding of the other aspects of their artistic production. On top of that, in the particular case of Ren, the fact that he decided to end his life in 2017 has probably still added ghoulish fascination towards his work, understanding his work from a romanticized approach.

Fig. 2. Ren Hang, 2012. Image courtesy of Ren Hang/ Galerie Paris-Beijing.

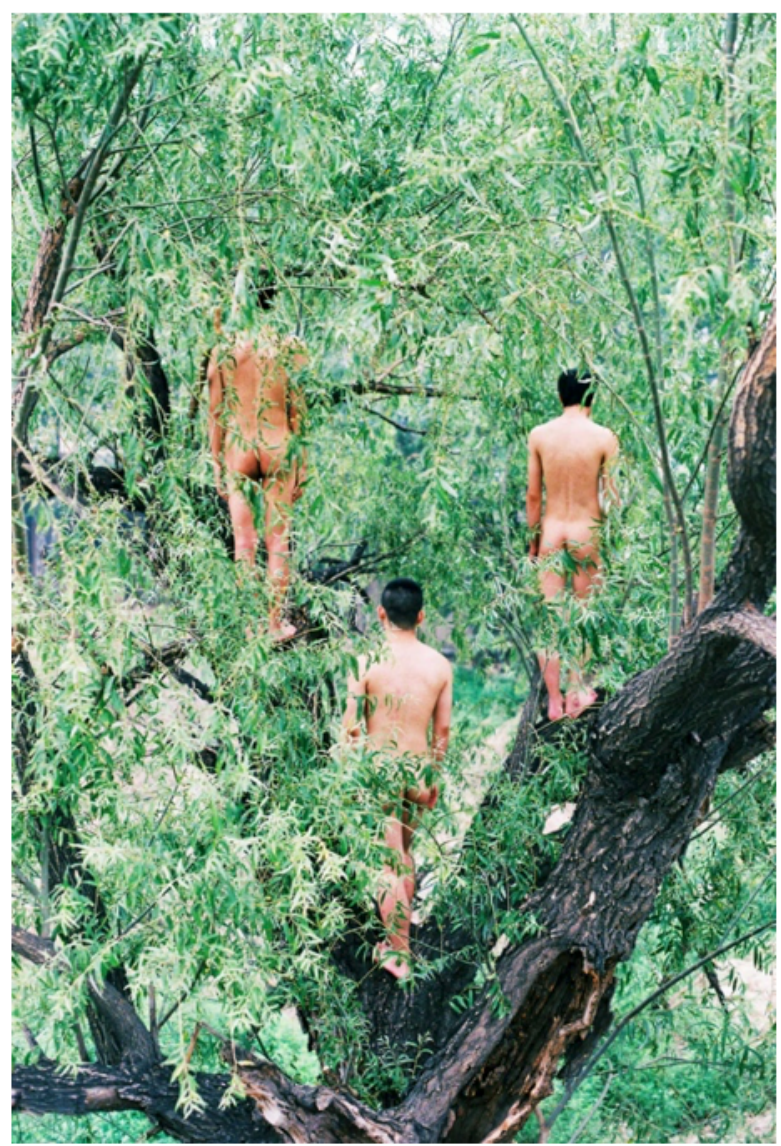

Still, Ren himself stated that he did not consider his work as ground-breaking or revolutionary, arguing that nudity is the most natural state of the human being. Ren Hang had a down-to-Earth approach in his photographic practice. In an interview with the British Journal of Photography, he argued that he used nudity so that he could feel more realism and sense of presence (2020). Ren felt that when taking pictures of people who were wearing clothes, they tried hard to present a certain image, so portraying them nude enabled a more direct and honest depiction of them. We can better understand his approach by reading an answer he gave in an interview with the magazine Medium: "We were born nude. So, talking about revolution, I don't think there's anything to revolutionize. Unless people are born with clothes on, and I want to take their clothes off, then I think this is a revolution" (Ren and Bernhardsson 2017). 
This naturalization of the naked body is specially underlined in the pictures taken outdoors in the wild nature, where models seemed to remind us of the animal condition of the human, hiding the models for example in between the trees (fig. 2). Also, in the same interview, in reaction to the fact that there is a tendency to directly equate the naked body with sex and pornography, he affirmed: "I don't like the word "erotica", I prefer "pornographic" I think it's more direct [...] I don't need to make it classy by calling it erotica. I don't think there is nothing wrong with low-class" (Ren and Bernhardsson 2017).

Nevertheless, even if Ren was comfortable with his photographs being identified as low-class, this chameleonic artist was also related to high fashion. The photographer collaborated with brands such as Gucci as well as fashion magazines, contributing to the idea that the images have nothing to do with the ordinary nor the vulgar (Anglès 2019). Yet, these depictions have also been described as low-class, comparing them with artist Yang Yong's series Fancy in Tunnel (2001- 2003) consisting of images of prostitutes in Shenzhen (Chen, 2018). There seems to be a thin line between the vulgar and the high-class, as his work has been approached from both. Still a point that reminds us of the debatable nature of his images, which remain exposed to new interpretations.

\section{GENDER, LAW AND PRESENCE}

Once Ren Hang's work reception and his own position has been explained, I aim to focus on gender and its apparent absence. For this purpose, in this section I combine the theoretical perspective on gender of some researchers, together with a poem by the artist himself.

When considering gender, convention has an important impact on its display. Judith Butler already suggested that the gendered position arises from being subjected to regulation, which leads to the naturalization of femininity and masculinity in each culture. This is a normativity from which gender is constructed and maintained, as Judith Butler asked:

Is there a gender that pre-exists its regulation, or is it the case that, in being subject to regulation, the gendered subject emerges, produced in and through that particular form of subjection? Is subjection not the process by which regulations produce gender? (Butler 2004, 41).

This question triggers the reader to reflect on the link between gender and regulation, trying to guess who came first, as the chicken-and-egg dilemma. The reader can implicitly understand the essential role of regulation and following those rules that create gender. In the case of Ren, he made short poems which were mostly about sexual intercourses but there were also some that talked about other topics such as "law". In the very short poem Hide-and-Seek, we can read as it follows:

Where there is no law,

I will hide there.

$($ Ren 2011) 6

The artist used the name of the "Hide-and-Seek" children game to reflect on law and hiding from it. A playfulness that could metaphorically be related to the way he also approached his artistic work as a shared cheerful moment, where law and gender were nowhere to be found. A playful tendency of hiding and omitting that was very common in his work, as it is shown for instance in an image where a model is trying to hide inside a suitcase (fig. 3). 
Going back to the gendered concern, this was visible even in some of Ren Hang's early works, where characteristics of gender fluidity could be identified, in terms of gender performativity related to clothing and make up. Ren's early works used to show people who were almost naked, in which the characteristics applied to normative binary genders were switched or combined in further exploration of oneself. Afterwards, ornaments disappeared, and the bodies were left naked. This naked factor underlined the bodily presence and its materiality, which is to be understood as a ground to be problematised in relation to gender (Butler 1993: 30). While it may be unsettling, it opened new possibilities for the material understanding of the body and its dynamic with gender.

Fig. 3. Ren Hang, 2011. Image courtesy of Ren Hang/ Galerie Paris-Beijing.

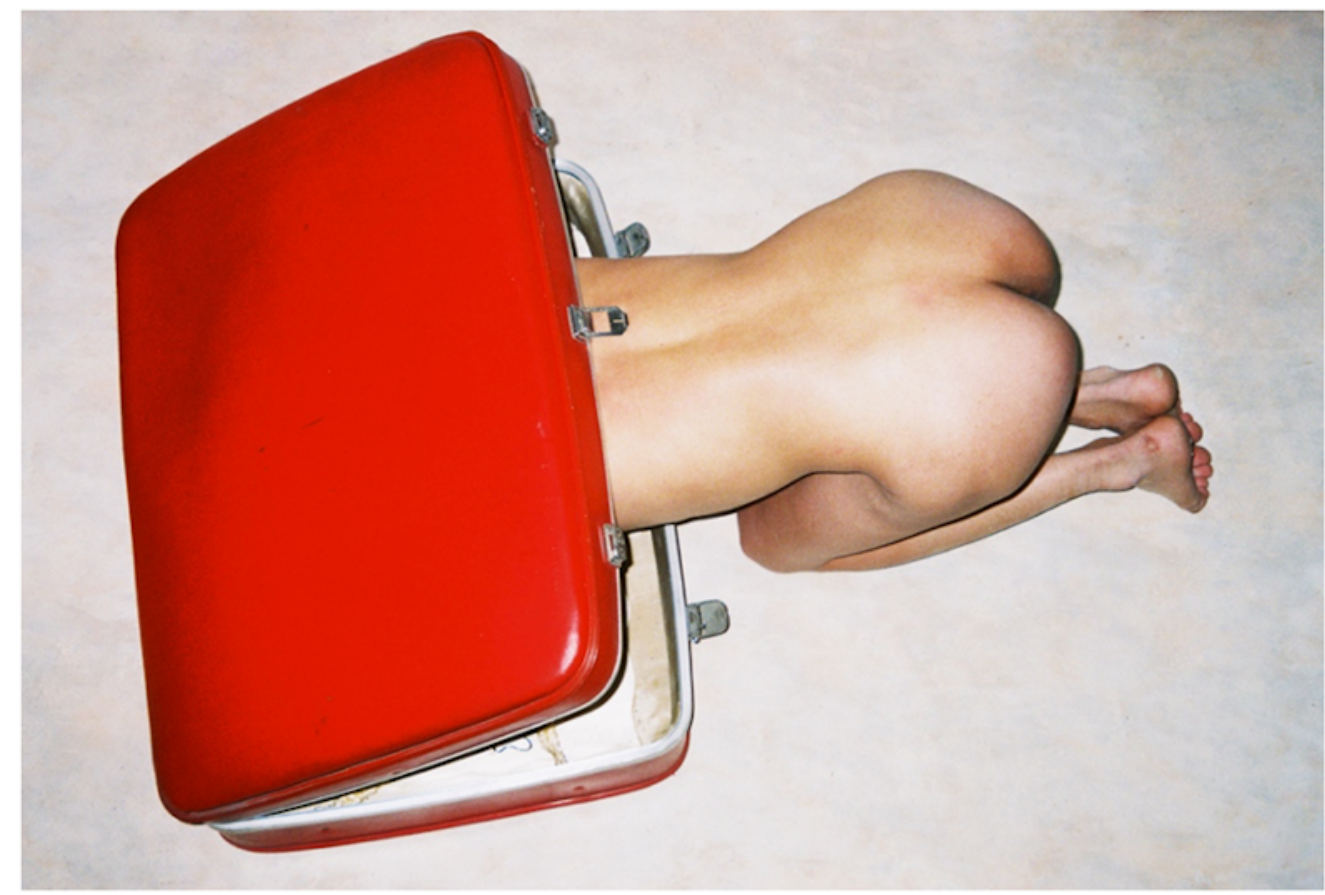

Related to this subject, Basia Sliwinska made a very interesting parallelism when comparing the Cheshire Cat from Alice's Adventures in Wonderland with gender. She suggested that representation is not only fluid but also happens between the presence and the absence, as it is not always there (Sliwinska 2016). In this way, by completely undressing and liberating the body from socially acquired artifices, elements of gender performativity are left out of the visual discourse. Also, the strangeness of the bodies makes it difficult to label them in relation to any gender, as Stephanie $\mathrm{H}$. Tung previously suggested (2017).

Therefore, Ren's work may propose a challenging alternative to the Western case of male subject/ gaze and female object dichotomy. In the classical Ways of Seeing, John Berger suggested that, especially in European oil paintings, men act, and women appear. To the extent that in looking to an oil painting, even if the viewer is a woman, she will probably have a socially male way of looking at the artwork $(1972,42)$. Indeed, Western aesthetic tradition has identified men with the reason, mind and spirit, women have been linked to the body, senses and desires, which is considered to be a lower category.

On the contrary, Chinese aesthetic tradition was about balance between body and mind. A harmonious balance derived and reinterpreted from the Confucian aesthetic experience, that can 
be useful for feminist aesthetics as Eva Kit-Wah Man suggests (2015). The close position behind the camera that Ren Hang once occupied, is now the place of the viewer. The subjects are so near to the camera, that it gives a very tactile feeling, as Thomas Dukes proposed in the interview, calling the viewer's body to experience the artwork, with no discrimination of the senses or gender in comparison with rationality ${ }^{7}$.

\section{TOWARDS A GENDERLESS VISUAL LANGUAGE}

\section{The influence of advertising aesthetics}

The treatment of the images responds also to a uniform aesthetic, that contribute to a potential genderless appreciation. Ren Hang received educated in the field of advertisement; thus, his visual language was probably influenced by his background. Indeed, I argue that the atemporality, uniformity and body fragmentation shown in his photographs (common in marketing), lead to a genderless reading.

Firstly, I would like to comment on the creation of atemporality through the use of flash, lack of decorations and centered composition. Ren's photographs had the capacity to stop the passage of time, which contrasts with the usual depictions of the body in Chinese art, where presence is perceived as rapidly coming and already passing away (Wiseman 2011, 131). The use of flash can be considered a contradictory signifier of the concept of atemporality, while at the same time being linked to instantaneity. The lack of any decorations in the images may give the feeling of an experimental laboratory, contributing to the non-gender-related nature of the spaces. In the same way, there is an important tendency to put the body in the center of the camera. These kinds of images may recall fashion magazines or advertisement techniques that put the focus on the product and avoid any potentially distracting elements, unless they add any significance on purpose.

When recalling Ren's photography, there is also a homogeneous type of bodies that may cross one's mind. This is to say young and gracefully thin bodies, generally showing clear skin and corresponding to Chinese people. The uniformity of the type of bodies may seem like a lack of diversity. It is important to acknowledge the fact that most of them were his friends, around \%70 he said in an interview (Berhardson 2012) or fans that wanted to pose for him and probably the youngest generation was more ready to pose naked for a photography. I suggest that this tendency to the depiction of homogeneous bodies contributes to genderless aesthetics, as projecting prejudices becomes more complicated with little possibility for comparison to be made.

Between the years 2010 and 2011, some of his early images used to capture mannequins. This may have been a sign towards the tendency of homogeneous body types used to create later compositions. The mannequins were photographed in a variety of quite visually aggressive ways: from lying on the street surrounded with litter and watermelons that seemed to almost be human flesh, to burning while wearing short hair wigs. The inexpressive mannequins may likewise share some resemblance with the later models facial expression. 
Fig. 4. Ren Hang, 2011. Image courtesy of Ren Hang/ Galerie Paris-Beijing.

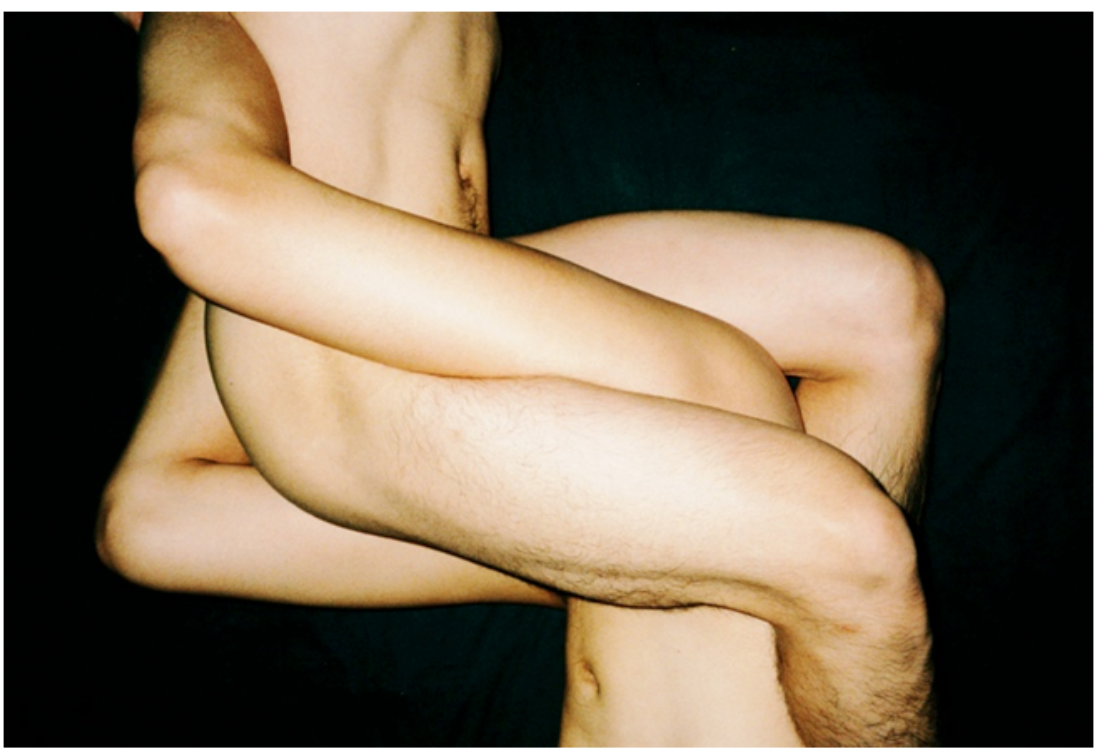

Exceptions to this body typology are the artworks he created with his mum as the main protagonist, and those for the fashion industry, which responded to the requirements of the people ordering. In those images there were people from various physical appearance are represented: in BAZAAR ART China and Aserica magazines Western looking models, in Atelier Rouge Pekin SS 15/16 a Chinese citizen with red hair, and in Elsewhere Magazine a black person.

It can also be said that body type homogeneity leads to deindividualization, which is reinforced through the use of symmetry and pose repetition. When showing people in a group, especially when they are undertaking similar or even synchronized actions, this can lead to deindividualization through uniform aesthetic. In the case of a photograph, symmetry can work as a rather efficient equivalent of timely synchronisation, as the same posture happens at the same time in the picture. This aesthetic leads to the negation of the self that was explored by Leslie Heywood. Heywood argued that the negation of the body and gender were part of what she considered anorexic aesthetics (1996), an effect emphasized through the symmetry of the composition as it can be appreciated in a photograph showing intertwined bodies (fig. 4).

The last resource employed in Ren's photography that can be interpreted as a useful tool inviting to a genderless reading is the use of the discomfort created by the fragmented body. In fact, the fragmentation of the body confronts the desire for voyeurism, as, not being able to access the whole of it, one part might make the viewer feel uncomfortable. Visual pleasure becomes a complicated aim to achieve in this context. Sometimes, it is the camera that fragments the body. At other times, it is the hiding game that makes the body fragmented. The lack of a head, and consequently a face, makes it slightly more difficult to recognize the owner of the body.

The tendency to fragment the body is closely related to advertisement of high fashion, an industry in which Ren had experience. Moreover, as the artist Yolanda Domínguez suggests, fragmentation can be perceived as a source of symbolic violence, influencing the visual experience of the audience; leading at the same time, towards an increase of violent attitudes within society (2021: para. 8). Within the selected images for this article, this visually aggressive tendency can particularly be appreciated in fig. 3 and fig. 5. On top of the discomfort that this may cause, the pictures were 
usually taken from quite a short distance. So, when staring at them, there is no way of avoiding the imaginatively fragmented body. A model that posed for Ren Hang nicknamed Lemon argued that as these images are not visible in daily life, they felt as if they are from a different world (VICE Japan 2013). Thus, it can be said that these postures are beyond the everyday body-language linked to gender.

\section{Conveying universal concepts: vulnerability through the fetal position}

In the following lines, I will explore the idea of vulnerability, in relation to how the artist uses the fetal position and how this contributes to undo gender conceptions. The notion of vulnerability is recurrent not only in Ren Hang's photography but also in his poetry. For example, in the poem I Am Empty from 2011, he expresses his fear of being attacked by someone from a faraway place:

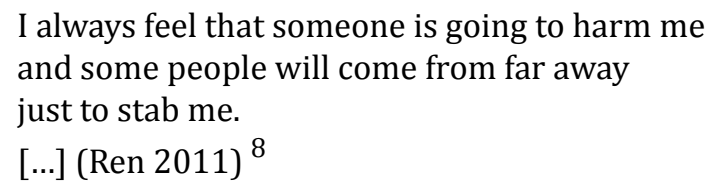

In reaction to the defenselessness expressed through this poem, the fetal position the models frequently adopt in the images becomes a symbol of protection, a kind of useful shell in a world of constant threats. With the reinforcement of the skin's protection and comfort, the fetal position instantly takes the viewer back to their mother's womb.

Also, the performance of this posture by a variety of models may suggest the idea of vulnerability as a universal experience for every human being which is not exclusive to femininity. In Chinese society, as well as others, closed body language is considered feminine and more open positions masculine. In the case of models posing for Ren Hang, this position is applied regardless of biological sex and socially acquired gender of the models.

Regarding the origins of this posture in the artist's work, the fetal position appears since his very first photographs in 2008, where a person is laying on a bed with their knees bent against their chest and their arms are embracing them. The early pictures were taken from a high position, visually increasing the vulnerability of the photographed individual. Yet, it is three years later in 2011 when the characteristic fetal pose composed by Ren Hang appears.

Like a flower bud, the models start gathering their extremities and heads together, with their backs serving as a shell. Even the head disappears in these compositions. This elimination erasing the face, which is a signal of personal recognition, leaves only the trunk of the body visible. Still, some interesting variants of this fetal posture can be found, which normally maintain the face hidden, while showing variations in relation to the position of arms and legs, as the picture of a model taken on the dry mud in 2012 (fig. 5). 
Figs. 5 and 6. Ren Hang, 2012.

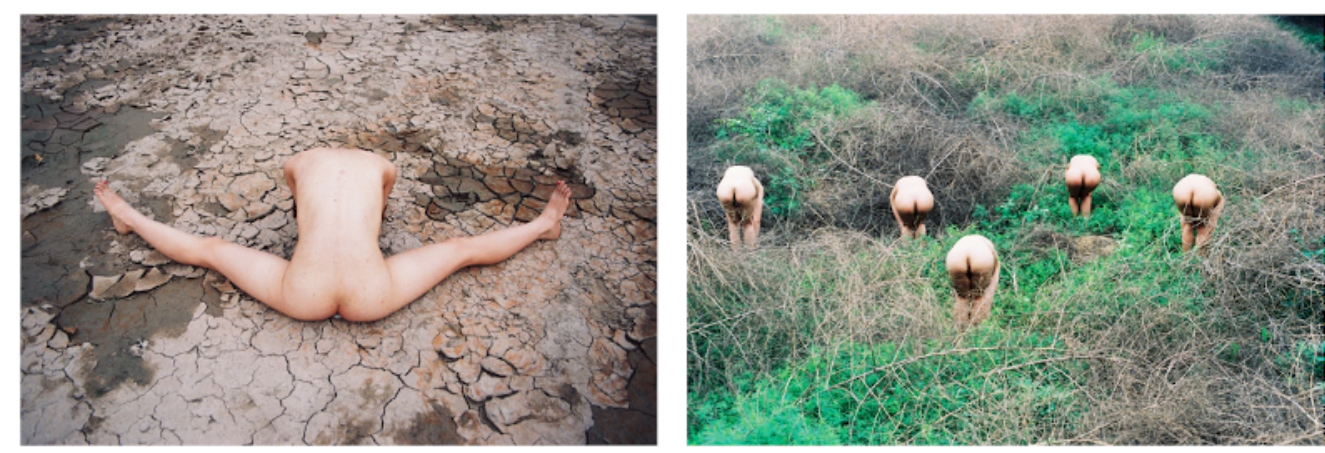

Images courtesy of Ren Hang/ Galerie Paris-Beijing.

The fetal posture, prospered later in 2014, a year presenting an increasing amount of them. When presented in nature, the models' heads could be seen, and it generally seemed like they were sleeping. When taken in interior spaces, pictures of these positions were more creative and their fragmentation more notable. Two years later in 2016, the fetal position appeared mostly in pictures taken outside. At that time, the fetal positions began to become more differentiated from human beings and seemingly creating new creatures. A relevant precedent of this tendency is shown in a picture dating from 2012 (fig. 6), where a group of bent bodies spread in the nature seem to be magical animals that have lost any gender and are just unapologetically existing.

\section{CONCLUSIONS}

Writing about genderless seems to me a challenging attempt, as its negation at the same time reminds us about the existence of a certain gender. This controversy can also be compared to the reception of Ren Hang's work, which has been considered from a variety of counterpoints, such as: revolutionary and natural, low-class and luxurious, superficial and meaningful. Now that the analysis of his work has entered the academic debates, it is to be hoped that interpretations on his vast legacy will continue to prosper.

The considerable number of photographs of more than a thousand, remain to be analysed, serving to provide material for understanding patterns and what tendencies the artist maintained, such as the erasure of gender. Through his own rules and by creating a visual language of repetitive patterns, he invited the viewers to feel uncomfortable. This position is a helpful one to be in, in order to be opened to navigate the absence of familiar gendered identifications that society is used to, living nowhere to hide.

I have argued that his previous formation in marketing may have had an influence in the development of his particular style. A style that was built around a renewed body language far from traditional conventions. No signs of time going by, as well as the centered position of the body with no more elements contouring it. This led to focus on the homogeneous body types that were orchestrated in playful manners that were not visible on daily life.

Also, together with the advertisement elements mentioned and the hiding technique, the convey of universal experience applied to any kind of model plays an important role in reeducating the viewer's eye towards a genderless logic. In this regard, the fetal posture has been an important element, as it is the closest body language possible and is related to vulnerability, an experience that 
in society is usually linked with female experience. This posture is endlessly repeated throughout his work and shows the way Ren used to work with models, unrelatedly to their gender.

Finally, I would like to note that Ren's photography guiding towards a reading of the genderless body, could be better understood by analyzing his early experimental years: when Ren Hang was playfully mixing gendered elements in the models before finally erasing these traits. Expectantly, in the following years this will be one of the several topics that his rich work will enable to write about. Until then, this article will hopefully serve as a starting point in what I consider to be one of the major contributions of his photographic practice, the creation of a genderless aesthetic.

\section{Acknowledgments}

I would like to acknowledge the University of the Basque Country UPV/EHU for its support through a PhD fellowship (PIFBUR19/02). I also thank Dr. Nuria Querol from Birmingham City University for her guidance through the Major Project of the M.A. Contemporary Arts China from which this article originated. Also, I would like to express my gratitude to Galerie Paris Beijing for facilitating the images to illustrate the article; and to editor Pierre Bessard as well as curator Thomas Dukes, who kindly accessed to meet and helped me to better understand the artist's work.

\section{REFERENCIAS}

Anglès, Daphné. “Ren Hang's Provocative Photographs Show a China We Rarely See." New York Times, March 5, 2019. https://www.nytimes.com/2019/03/05/arts/design/ren-hang-paris.html.

Berger, John. Ways of Seeing. London: British Broadcasting Association and Penguin, 1972.

Butler, Judith. Undoing gender. London and New York: Routledge, 2004.

- - - "Bodies that matter." In Bodies that matter: On the Discursive Limits of Sex, 27-57. New York: Routledge, 1993.

British Journal of Photography. “An Interview with Ren Hang." February 27, 2017. https://www.bjp-online. com/2017/02/an-interview-with-ren-hang/.

Chen, Shuxia. "Ren Hang: Bodies Without Redemption." Gilded Age: A Year of Chinese Labour, Civil Society, and Rights, Made in China Yearbook 2017, edited by Ivan Franceschini and Nicholas Loubere, 200-205. Camberra: ANU Press, 2018.

Domínguez, Yolanda. “Capítulo 5: Moda.” In Maldito estereotipo Barcelona: Ediciones B, 2021. Kindle edition. Elkins, James. Photography theory. London and New York: Routledge, 2007.

Gamso, Nicholas. "Ren Hang in the Global City." Ideas: Journal of The Asia Art Archive, January 24, 2019. http s://aaa.org.hk/en/ideas/ideas/Ren-Hang-In-The-Global-City/.

Genova, Alexandra. "Ai Weiwei Reflects on the Sadness of Ren Hang's Photographs." Time, March 7, 2017. $\underline{\mathrm{h}}$ ttps://time.com/4688548/ai-weiwei-ren-hang/.

Heywood, Leslie. Dedication to Hunger: The Anorexic Aesthetic in Modern Culture. Berkeley, Los Angeles and oxford: University of California Press, 1996.

Kristof, Nicholas. D. "Beijing Journal; Freshest Nuance in China's Art is (Blush) Nudes." New York Times, January 9, 1989. https://www.nytimes.com/1989/01/09/world/beijing-journal-freshest-nuance-in-c hina-s-art-is-blush-nudes.html.

Liang, Chengyu. “Remembering Ren Hang's High-Contrast Charisma." Sixth Tone, August 18, 2017. http://si xthtone.com/news/1000708/remembering-ren-hangs-high-contrast-charisma. 
Mumford, Stephen. "A Pornographic Way of Seeing." In Pornographic Art and the Aesthetics of Pornography, edited by Hans Maes, 58-72. Basingstoke: Palgrave Macmillan, 2013.

Man, Eva Kit Wah. "Some Reflections on Confucian Aesthetics and Its Feminist Modalities," In Issues of Contemporary Art and Aesthetics in Chinese Context, 29-35. Berlin and Heidelberg: Springer, 2015.

“Naked and afraid." The Economist, January 7, 1989. http://link.galegroup.com/apps/doc/A7054644/STN $\mathrm{D} ? \mathrm{u}=\mathrm{uce} \& \operatorname{sid}=\mathrm{STND} \& \mathrm{xid}=42 \mathrm{a} 6$.

Quondamatteo, Ada. “Cuori Teneri: (心肠软 (Xīncháng Ruăn). Rifflesioni su Ren Hang,” BA diss., Univeristy of Bologna, 2020.

Ren, Hang and N. E. O. Bernhardsson “Ren Hang.” Medium, January 30, 2017. https://medium.com/vantag e/ren-hang-2012-eccbf96b136c .

Ren, Hang and Dian Hanson. Ren Hang. Cologne: Taschen, 2016.

Ren, Hang and Brad Feuerhelm. "Ren Hang and the Production of the Hidden Idealized Body in China." ASX, April 22, 2015. https://www.americansuburbx.com/2015/04/ren-hang-and-the-production-of-the-h idden-idealized-body-in-china.html.

Sliwinska, Basia. The Female Body in the Looking-Glass : Contemporary Art, Aesthetics and Genderland. London, New York: I. B. Tauris \& Company Limited, 2016.

Tung, Stephanie. H. "The Subversive Fantasies of Ren Hang (1987--2017)." Aperture, February 24, 2017. ht tps://aperture.org/blog/remembering-ren-hang/.

VICE Japan, “The Art of Taboo: 任航（レン・ハン - Ren Hang” Youtube video, 3’32 and 4'20', September 2, 2013,

https://www.youtube.com/watch?v=FdnZlynWFMs\&ab_channel=VICEJapan.

$\mathrm{Xu}$ Jiachen. "Queer of Colour, Becoming (with) Nonhuman,” MA diss., University of Oviedo, 2018.

Wiseman, Mary Bittner, “Gendered bodies in contemporary Chinese art." In Chinese Art. Subversive Strategies in Contemporary Chinese Art: Philosophy of History and Culture, edited by Liu Yuedi and Mary Bittner Wiseman, 125-146. Leiden: Brill Academic Publishing, 2011.

Wu, Hung and Wang Peggy, Contemporary Chinese Art: Primary Documents, Durham, N. C.: Duke University Press, 2010.

Notes

1 This source was part of the exhibition held at the Maison de la Photographie Européenne in 2019 that is later discussed.

2 Dukes, Thomas. interview by author, Liverpool, June 4, 2019.

3 The first Fuck Off exhibition was organised by Ai Weiwei and Feng Boyi in Shanghai in the year 2000. It was held as a counter-exhibition parallel to the Shanghai Biennial. Some of the artworks that were going to be shown were banned from being exhibited, due to nude depictions or protest content.

$4 \quad$ None of the photographs were purposely given a title by the autor. For this reason, through this article they can only be identified with the year.

5 Bessard, Pierre, interview by author, Paris, June 21, 2019.

6 The poems were to be found classified yearly within the website. Nevertheless, this resource was deleted by the family after his decease. The poem dates from September 5, 2011. The original text is as it follows: 《捉迷 藏》那里没有法律 / 我就躲在那里.

7 Dukes, Thomas. interview by author, Liverpool, June 4, 2019.

8 The poem dates from December 28, 2011. The original text is as it follows: 《我空虚》我总觉得有人要来害 我, / 而且有的人要从很远的地方来找我, / 就为了捅我一刀 .... 